\title{
Capsule Commentary on Nicolaidis et al., The Development and Evaluation of an Online Healthcare Toolkit for Autistic Adults and their Primary Care Providers
}

\author{
Jeffrey L. Jackson, MD, MPH \\ Zablocki VAMC, Milwaukee, WI, USA. \\ J Gen Intern Med 31(10): 1219 \\ DOI: $10.1007 / \mathrm{s} 11606-016-3834-8$ \\ (c) Society of General Internal Medicine 2016
}

A utism is usually diagnosed and managed in childhood, but it is a lifetime condition, and as autistic children age they find that resources and services for autistic adults are rare and providers are ill-trained to care for them. ${ }^{1}$ Autistic adults have unique barriers to healthcare; even making an appointment and getting to their doctor's office can be overwhelming. Into this void, these researchers used a community-based participatory research (CBPR) approach to develop an online toolkit for autistic adults and their providers. ${ }^{2}$ This report describes the process of developing and evaluating the material included in the toolkit. They found that the tools were reliable and valid and that autistic patients and their providers found the kit easy to use. In the field, the toolkit reduced patient perceptions of care barriers and improved healthcare self-efficacy (slightly) and patient satisfaction. Providers reported the information to be very (52\%) or somewhat (43\%) useful. These outcomes are limited by being based on surveys; no data were collected to determine whether autistic adults received higher quality healthcare or had an improved ability to navigate the healthcare system.

Nonetheless, for most primary care providers, an encounter with an autistic adult is likely to be frustrating. PCPs may not know how to communicate effectively. The online toolkit (http://autismandhealth.org) has both patient and provider portals. The patient portal includes tools to help autistic adults prepare a letter explaining their unique problems and checklists autistic adults can use before and after the visit to improve the quality of their healthcare. The provider portal includes information about the unique healthcare needs of autistic adults and tips on how to improve communication. It also includes a visual pill schedule that includes pictures to help explain why the patient is taking certain medications.

This body of work represents an important contribution for providers struggling to care for autistic adults and for autistic adults struggling to communicate their care needs to their providers. It also demonstrates a superb example of using CBPR methods to improve healthcare. Future research should examine whether the toolkit improves care quality or improves patient and provider comfort with encounters.

Corresponding Author: Jeffrey L. Jackson, MD, MPH; Zablocki VAMC, Milwaukee, WI, USA (e-mail: jjackson@mcw.edu).

\section{Compliance with ethical standards:}

Conflict of interest: The author declares that he does not have a conflict of interest.

\section{REFERENCES}

1. Zerbo O, Massolo ML, Gian Y, Croen LA. A study of physician knowledge and experience with autism in adults in a large integrated healthcare system. J Autism Dev Disord. 2015;45(12):4002-14.

2. Nicolaidis C, Raymaker D, McDonald $\mathbf{K}$, Kapp S, Weiner $\mathbf{M}$, Ashkenazy E, Gerrity M, Kripke C, Platt L, Baggs A. The development and evaluation of an online healthcare toolkit for autistic adults and their primary care providers. J Gen Intern Med. 2016. doi:10.1007/s11606016-3763-6.

Published online August 10, 2016 